\title{
DEGRADATION OF TRICHLOROETHYLENE AND PERCHLOROETHYLENE BY A ZERO-VALENT IRON PERMEABLE REACTIVE BARRIER: PRELIMINARY TESTS
}

\author{
S. FIORE \& M. ZANETTI \\ DITAG, Politecnico di Torino, Italy.
}

\section{ABSTRACT}

Zero-valent iron materials may be employed with high contaminant removal efficiency in permeable reactive Barriers (PRBs) for the remediation of chlorinated solvents in groundwater. The basis of this in situ cleanup technology is simple: the groundwater flow passes through the reactive substrate and the chlorinated solvents are converted by means of oxidation-reduction processes to nontoxic hydrocarbons, such as alkanes and alkenes, and chloride ions. Two cast iron aggregates (WSR size 8/50 and Brown size 8/50, from Peerless Powders and Abrasive Inc.) are evaluated in this work as a substrate for a PRB, proposed as remediation technology for a polluted site in which the main contaminants are perchloroethylene (PCE) and trichloroethylene (TCE). The zero-valent materials were characterized by means of particle-size analysis, and some batch tests, considering different equilibrating periods, were performed. The used aqueous phase had a chemical composition very similar to the polluted groundwater and it contained PCE and TCE concentrations equal to the maximum values detected in the site $(7.52 \mathrm{mg} / \mathrm{l}$ of PCE and $6.65 \mathrm{mg} / \mathrm{l}$ of TCE). The leaching of metals from the reactive substrates and the effect of dissolved salts on the life of the PRB were also evaluated. The Brown material appeared to be more efficient than the WSR material in TCE degradation and more efficient with TCE compared to PCE, probably because of a competitive effect between the pollutants. No toxic metals were released in the aqueous phase. This study confirmed the efficiency of zero-valent iron materials in the remediation of chlorinated solvents.

Keywords: perchloroethylene, permeable reactive barriers, reductive dechlorination, trichloroethylene, zerovalent iron.

\section{INTRODUCTION}

Zero-valent iron permeable reactive barriers (PRBs) have been studied and developed from the early 1990s for the remediation of groundwater polluted by chlorinated organics (i.e. chlorinated alkenes, alkanes, phenols and other aromatics) [1,2]. The basis of this in situ cleanup technology is easy: the groundwater flow passes through the reactive substrate moving under natural or induced hydraulic gradients, as shown in Fig. 1, and chlorinated solvents are converted by reduction processes to nontoxic hydrocarbons, such as alkanes and alkenes, and chloride ions.

The main advantages of PRBs are their easy construction and management, high efficiency even in the presence of several pollution sources, high removal rate and no waste production (except the building phase). A complete characterization of the polluted site, based on the investigation of the aquifer physical characteristics (depth and thickness of the impermeable layer, hydraulic gradient and permeability), of the water geochemistry ( $\mathrm{pH}$, conductivity, dissolved oxygen, sulfates, nitrates and chlorides, total hardness and the presence of heavy metals) and of the pollutant plume characteristics (depth, width, velocity and quantity and identity of pollutants), is necessary for a correct PRB dimensioning $[3,4]$.

Cast iron materials, the reagent medium in PRBs, are particularly efficient in the degradation of chlorinated solvents: the zero-valent iron acts as a reducing agent, transferring electrons to chlorinated compounds by surface oxidation-reduction processes, according to reactions (1) and (2), in which $\mathrm{R}-\mathrm{Cl}$ is a chlorinated alkyl compound. Zero-valent metals are considered electron donors and water is a proton donor. The net effect of a two-electron transfer in the pollutant molecule is the replacement 


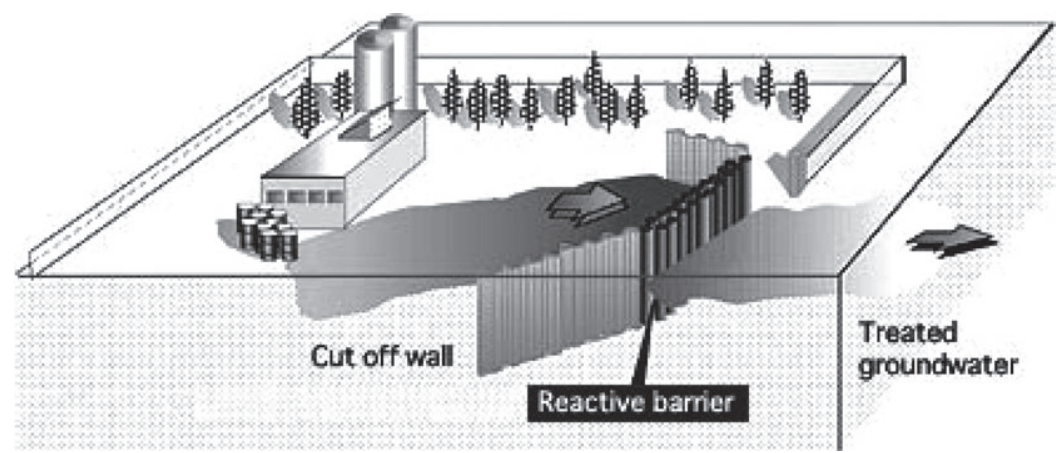

Figure 1: Operating principle of a PRB.

of a chlorine atom with a hydrogen atom, with the concomitant liberation of a chloride ion, as shown in the comprehensive reaction of hydrogenolysis $(3)[1,5-8]$.

$$
\begin{gathered}
\mathrm{Fe}^{0} \rightarrow \mathrm{Fe}^{2+}+2 \mathrm{e}^{-} \\
\mathrm{R}-\mathrm{Cl}+2 \mathrm{e}^{-}+\mathrm{H}^{+} \rightarrow \mathrm{R}-\mathrm{H}+\mathrm{Cl}^{-} \\
\mathrm{Fe}^{0}+\mathrm{R}-\mathrm{Cl}+\mathrm{H}^{+} \rightarrow \mathrm{Fe}^{2+}+\mathrm{R}-\mathrm{H}+\mathrm{Cl}^{-}
\end{gathered}
$$

The remediation process consists of a series of reactions leading to the progressive dehalogenation of the chlorinated substance to the conversion of the pollutant to alkanes and alkenes.

Zero-valent iron is the most used and widely studied reactive material for PRBs, because of its high reductive efficiency by means of a first order kinetic $[6,9,10]$, the absence of toxic by-products and a relatively low cost.

Dechlorination processes by zero-valent iron happen in acidic environments and involve a $\mathrm{pH}$ enhancement, because hydrogen ions substitute chlorides in pollutant molecules (see reaction (3)). Some species dissolved in groundwater, such as carbonic acid (see reaction (4)), bicarbonates (see reaction (5)), dissolved oxygen (see reaction (6)) and sulfates (see reaction (7)), and also water itself (see reaction (8)), may accelerate zero-valent iron corrosion, according to the following reactions $[6,11-13]$ and result in increased $\mathrm{pH}$ (see reactions (6)-(8)):

$$
\begin{gathered}
\mathrm{Fe}^{0}+2 \mathrm{H}_{2} \mathrm{CO}_{3} \rightarrow \mathrm{Fe}^{2+}+2 \mathrm{HCO}_{3}^{-}+\mathrm{H}_{2} \\
\mathrm{Fe}^{0}+2 \mathrm{HCO}_{3}^{-} \rightarrow \mathrm{Fe}^{2+}+2 \mathrm{CO}_{3}^{2-}+\mathrm{H}_{2} \\
\mathrm{Fe}^{0}+1 / 2 \mathrm{O}_{2}+\mathrm{H}_{2} \mathrm{O} \rightarrow \mathrm{Fe}^{2+}+2 \mathrm{OH}^{-} \\
2 \mathrm{Fe}^{0}+\mathrm{SO}_{4}^{2-}+10 \mathrm{H}^{+} \rightarrow 2 \mathrm{Fe}^{2+}+\mathrm{H}_{2} \mathrm{~S}+4 \mathrm{H}_{2} \mathrm{O} \\
\mathrm{Fe}^{0}+2 \mathrm{H}_{2} \mathrm{O} \rightarrow \mathrm{Fe}^{2+}+\mathrm{H}_{2}+2 \mathrm{OH}^{-}
\end{gathered}
$$

As $\mathrm{pH}$ increases, and redox potential (Eh) decreases as a consequence of iron corrosion (groundwater Eh is usually around $200-400 \mathrm{mV}$, while in contact with zero-valent iron, Eh may reach values of about $-500 \mathrm{mV}$ due to the reductive environment according to Gillham et al. [9]), bicarbonates convert to carbonates to buffer the $\mathrm{pH}$ increase. Carbonates then combine with the dissolved cations 


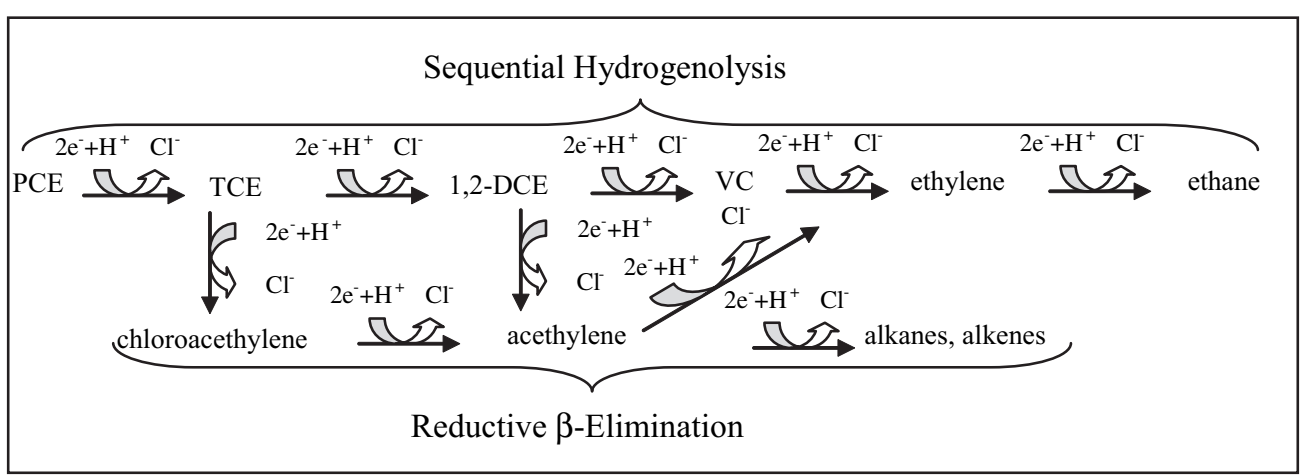

Figure 2: Degradation pathways of perchloroethylene (PCE) and trichloroethylene (TCE).

to form precipitates on the surface of zero-valent iron particles [14]:

$$
\begin{aligned}
\mathrm{Ca}^{2+}+\mathrm{CO}_{3}^{2-} & \rightarrow \mathrm{CaCO}_{3}(\mathrm{~s}) \\
\mathrm{Fe}^{2+}+\mathrm{CO}_{3}^{2-} & \rightarrow \mathrm{FeCO}_{3}(\mathrm{~s}) \\
\mathrm{Mg}^{2+}+\mathrm{CO}_{3}^{2-} & \rightarrow \mathrm{MgCO}_{3}(\mathrm{~s})
\end{aligned}
$$

The life of PRBs have been investigated in field studies: a decrease of iron reactivity over time due to the formation of a surface passivation layer made of amorphous iron hydroxides, carbonates and other corrosion products has been observed [11, 13-15].

In this work, the performances of two cast iron aggregates (WSR size 8/50 and Brown size 8/50, purchased from Peerless Powders and Abrasive Inc., Detroit, US) are experimentally tested, hypothesizing the installation of a zero-valent iron PRB in a polluted site located in the area of Florence (Central Italy). The main contaminants in the site, the property of a firm that distributes industrial solvents, are perchloroethylene (PCE) and trichloroethylene (TCE), both carcinogenic compounds characterized by a low mobility and a long persistence in the aquifer.

After the dechlorination of PCE to TCE, the degradation of TCE can follow two different pathways as shown in Fig. 2: sequential hydrogenolysis through 1,2-dichloroethylene (1,2-DCE), mainly the cis isomer, then vinyl chloride (VC), ethylene and ethane; or reductive $\beta$-elimination through chloroacethylene, acethylene and, finally, alkanes and alkenes. Usually, the fastest and predominant degradation mechanism is the reductive $\beta$-elimination $[16,17]$.

The compared zero-valent iron materials were characterized by means of particle-size analysis and determination of specific surface area, and some batch tests were performed using an aqueous phase having a chemical composition very similar to the polluted groundwater, regarding $\mathrm{pH}$ and dissolved salts, and containing PCE and TCE concentrations equal to the maximum values detected in the site $(7.52 \mathrm{mg} / \mathrm{l}$ of PCE and $6.65 \mathrm{mg} / \mathrm{l}$ of TCE). The values of $\mathrm{pH}$, electric conductivity (EC), Eh and the concentration of chlorides, sulfates and some metals (sodium, magnesium, iron, manganese, zinc, chromium, nickel, lead, copper, cadmium, cobalt and aluminum) were monitored to evaluate the leaching of metals from the reactive substrates and the effect of dissolved salts on the life of the PRB. The required PRB thickness (i.e. the thickness necessary to lower the pollutant concentration under the Italian law DM 471/1999 limits for groundwater, equal to $1.5 \mathrm{ppb}$ for TCE and to $1.1 \mathrm{ppb}$ for PCE) was calculated employing the gathered kinetic constant values. 


\section{EXPERIMENTAL METHOD}

Two zero-valent iron materials (WSR size 8/50 and Brown size 8/50, purchased from Peerless Powders and Abrasive Inc., Detroit, MI, US) were characterized by means of particle-size analysis carried out on samples of about $5 \mathrm{~kg}$, which were reduced to a mass of about $200 \mathrm{~g}$ with a Jones splitter and a Ro-Tap Tyler mechanical siever.

An aqueous phase having a chemical composition very similar to the polluted groundwater, with respect to $\mathrm{pH}$ (equal to 7) and dissolved salts, was prepared in distilled water by dissolving $\mathrm{NaCl}$ and $\mathrm{MgSO}_{4} \cdot 7 \mathrm{H}_{2} \mathrm{O}$, and adding 1 to 3 drops of $1 \mathrm{~N} \mathrm{NaOH}$ and $\mathrm{HCl}$ standard solutions to adjust the $\mathrm{pH}$ value. This artificial groundwater was used in batch tests.

On the polluted aqueous phase resulting from the batch tests, PCE and TCE concentrations, $\mathrm{pH}$, Eh, EC and the concentration of chlorides, sulfates and several metals ( $\mathrm{Na}, \mathrm{Mg}, \mathrm{Fe}, \mathrm{Mn}, \mathrm{Zn}, \mathrm{Cr}, \mathrm{Ni}$, $\mathrm{Pb}, \mathrm{Cu}, \mathrm{Cd}$ and $\mathrm{Co}$ ) were analyzed. The same parameters were measured on the blanks obtained, performing the batch tests on artificial groundwater and the two zero-valent materials, in the absence of chlorinated pollutants, to evaluate the leaching from the substrates.

The $\mathrm{pH}$ values were measured with an Orion 420A pH-meter, the Eh values with an Orion SA520 potentiometer and the EC values with a WTW LF 538 conductimeter.

The concentrations of some metals were measured using industrially coupled plasma optical emission spectrometry with a Perkin-Elmer Optima 2000 DV spectrometer.

The chloride and sulfate contents were evaluated with a Unicam Helios $\alpha$ UV-Visible molecular spectrometer, using a colorimetric method for chlorides and a turbidimetric method for sulfates (APHA, AWWA, WPCF [18]).

The PCE and TCE concentrations were analyzed using headspace gas chromatography, with an HP4890 instrument equipped with an ECD and an HP-5 capillary column $(15 \mathrm{~m} \times 0.53 \mathrm{~mm} \times$ $1.5 \mu \mathrm{m}$ ). $250 \mu \mathrm{l}$ of headspace was injected splitless (injector temperature equal to $200^{\circ} \mathrm{C}$ ), by means of a Hamilton $250 \mu \mathrm{l}$ gastight syringe. The headspace sample was collected keeping a vial and the syringe, sampling $250 \mu \mathrm{l}$, at $60^{\circ} \mathrm{C}$ for $30 \mathrm{~min}$. The following temperature program was performed for the gaschromatographic analyses: $40^{\circ} \mathrm{C} / 4 \mathrm{~min}$, then heating at $3{ }^{\circ} \mathrm{C} / \mathrm{min}$ till $50^{\circ} \mathrm{C}$, $50^{\circ} \mathrm{C} / 1 \mathrm{~min}$, then heating at $50^{\circ} \mathrm{C} / \mathrm{min}$ till $185^{\circ} \mathrm{C}$, finally $185^{\circ} \mathrm{C} / 1 \mathrm{~min}$. The gas chromatograph was calibrated daily with a minimum of three calibration standards of PCE and TCE concentrations similar to the ones of the samples of the day, and duplicate vials were prepared for each standard.

\subsection{Preparation of stock solutions and standards}

A mother solution containing PCE $(20768 \mathrm{mg} / \mathrm{kg})$ and TCE $(18577 \mathrm{mg} / \mathrm{kg})$ in methanol ( $>99.8 \%$ for GC analyses, purchased from Fluka Chemie $\mathrm{GmbH}$ ) was prepared by weighing on a Mettler Toledo balance $(0.0001 \mathrm{~g}$ sensitivity) from PCE and TCE $>99.9 \%$ GC standards, purchased from Fluka Chemie GmbH.

Three stock solutions containing both pollutants $(2165 \mathrm{mg} / \mathrm{kg}$ of PCE and $1926 \mathrm{mg} / \mathrm{kg}$ of TCE, $199 \mathrm{mg} / \mathrm{kg}$ of PCE and $182 \mathrm{mg} / \mathrm{kg}$ of TCE, $11 \mathrm{mg} / \mathrm{kg}$ of PCE and $17 \mathrm{mg} / \mathrm{kg}$ of TCE, respectively) were prepared in methanol by weighting from the mother solution. From the injection of $10 \mu 1$ of these stock solutions and of the mother solution in $20 \mathrm{ml}$ of distilled water sealed in a $20 \mathrm{ml}$ headspace vial, the following calibration standards were prepared daily: $4 \mu \mathrm{g} / \mathrm{l}$ of PCE and $7 \mu \mathrm{g} / \mathrm{l}$ of TCE, $11 \mu \mathrm{g} / \mathrm{l}$ of PCE and $16 \mu \mathrm{g} / \mathrm{l}$ of TCE, $79 \mu \mathrm{g} / \mathrm{l}$ of PCE and $72 \mu \mathrm{g} / \mathrm{l}$ of TCE, $856 \mu \mathrm{g} / \mathrm{l}$ of PCE and $762 \mu \mathrm{g} / \mathrm{l}$ of TCE, $8220 \mu \mathrm{g} / \mathrm{l}$ of PCE and $7350 \mu \mathrm{g} / \mathrm{l}$ of TCE in distilled water. 


\subsection{Procedure of batch tests}

The starting concentrations of the pollutants were always the same $(7.52 \mathrm{mg} / \mathrm{l}$ of PCE and $6.65 \mathrm{mg} / \mathrm{l}$ of TCE), and the batch tests were performed considering different equilibrating periods ( 2 and $6 \mathrm{~h}$, $1,2,3,5,7,10,13,15$ and 18 days) at a temperature equal to $20^{\circ} \mathrm{C}$. For each period, three samples containing artificial groundwater, PCE and TCE and zero-valent iron material (a solid/liquid ratio equal to 1:4 was chosen, according to Gillham et al. [9], and two method blanks containing artificial groundwater, PCE and TCE were prepared. The method blanks were analyzed to evaluate eventual losses of pollutants independent from the reagent materials.

In the preparation of samples, $5 \mathrm{~g}$ of zero-valent iron were weighted $(0.01 \mathrm{~g}$ sensitivity) in a $20 \mathrm{ml}$ vial, then completely filled with artificial groundwater, avoiding any bubble formation, and sealed. The sealed vial was then contaminated injecting through the septum $10 \mu \mathrm{l}$ of mother solution, and the equilibrating period was carried out with a Stuart Scientific Rotator Drive STR4/1 rotating at a speed of $10 \mathrm{rpm}$. After the equilibrating period, $5 \mathrm{ml}$ of the aqueous phase was sampled with a $5 \mathrm{ml}$ Hamilton syringe, using a second needle to compensate the pressure, and transferred into a $10 \mathrm{ml}$ headspace vial, already sealed and containing $1 \mathrm{~g}$ of $\mathrm{NaCl}$. This vial was then heated at $60^{\circ} \mathrm{C}$ for 30 min with a Hamilton gastight syringe sampling $250 \mu \mathrm{l}$ of headspace.

In the preparation of method blanks (to evaluate leaching of chlorinated solvents from the vials), $20 \mathrm{ml}$ of artificial groundwater, sealed in a $20 \mathrm{ml}$ headspace vial, was contaminated with $10 \mu \mathrm{l}$ of mother solution and the equilibrating period and further operations were carried out together with the samples.

The batch tests were performed also preparing reagent blanks, with artificial groundwater and zero-valent iron materials, in the absence of chlorinated pollutants, to evaluate leaching from reagent substrates.

\section{RESULTS AND DISCUSSION}

The results of particle-size analyses are shown in Fig. 3: no relevant differences may be noted between the two zero-valent iron substrates. A larger particle-size dimension characterizes the Brown material with an involved lower specific surface area $\left(1.90 \mathrm{~m}^{-1}\right)$ compared to the WSR sample $\left(2.11 \mathrm{~m}^{-1}\right)$.

Batch tests, although not representative of the phenomena happening in PRB at a real scale (because in batch tests solid/liquid contact is optimized, and solid/liquid ratio is lower than in a PRB), are very useful for a preliminary evaluation of the dechlorination efficiency of a reagent material in the chosen boundary conditions (pollutants' concentration, $\mathrm{pH}$ and chemical composition of polluted groundwater). The degradation of chlorinated organics by zero-valent iron materials is usually expressed by means of a first order kinetic equation $[6,9,10])$ :

$$
\frac{\mathrm{d} C}{\mathrm{~d} t}=-k C .
$$

The solution of eqn (12) is the following:

$$
\ln \frac{C}{C_{0}}=-k t,
$$

where $C_{0}$ and $C$ are, respectively, the initial and the final pollutant concentration values and $k$ is the first order kinetic constant.

In the analyses of PCE and TCE concentrations, the values obtained from the blanks were used to calculate the initial pollutant concentrations $C_{0}$ for each period $t$, and the values obtained from the samples were used to calculate the final pollutant concentrations for the same period $t$ in eqn (13). 


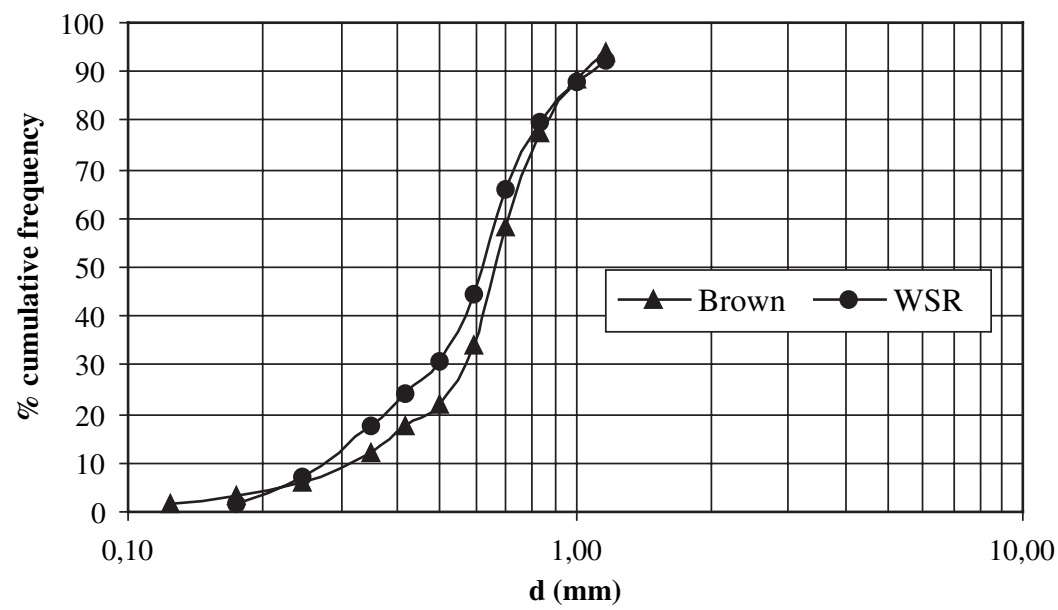

Figure 3: Particle-size curves of the zero-valent iron materials.

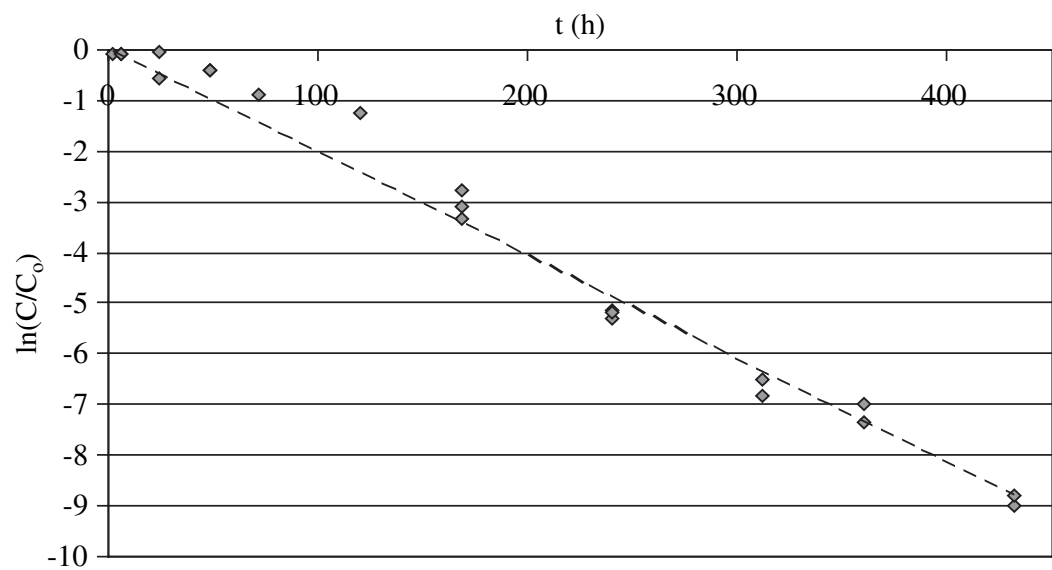

Figure 4: Degradation of TCE $(6.65 \mathrm{mg} / \mathrm{l})$ by the Brown zero-valent iron material. The dotted line represents the best fit using a first order kinetic model.

A least squares regression of the experimental data allowed the calculation of the first order kinetic constant $(k)$. The first order kinetic constant values, found in literature on reductive dechlorination by zero-valent iron materials, are between 0.003 and $0.08 \mathrm{~h}^{-1}$ for PCE and between 0.004 and $1.73 \mathrm{~h}^{-1}$ for TCE $[10,12,19]$.

The degradation curves of PCE and TCE obtained for the Brown and the WSR materials are shown in Figs 4-7.

TCE dechlorination by both reagent materials can be expressed using a first order kinetic model: the regression coefficients are satisfactory and the kinetic constants (see Table 1) are in agreement with data in the literature.

PCE dechlorination by both reagent materials cannot be expressed using a first order kinetic model: the process is very fast, more than for TCE, until more than $100 \mathrm{~h}$ of the batch tests for the Brown material, and until more than $150 \mathrm{~h}$ for WSR material; the rate then decreases, making the 


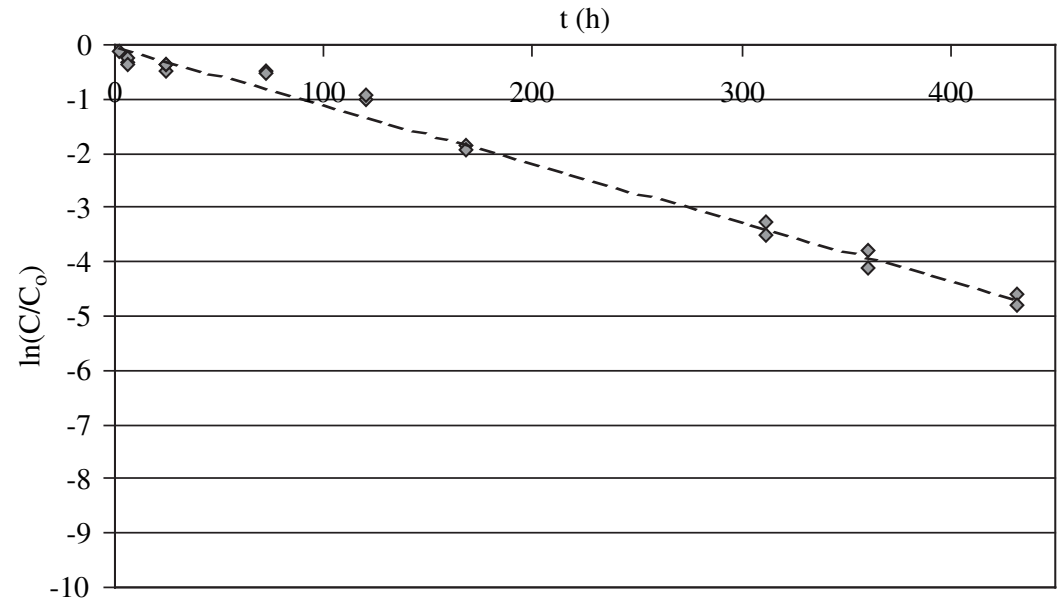

Figure 5: Degradation of TCE ( $6.65 \mathrm{mg} / \mathrm{l})$ by WSR zero-valent iron material. The dotted line represents the best fit using a first order kinetic model.

$\mathrm{t}(\mathrm{h})$

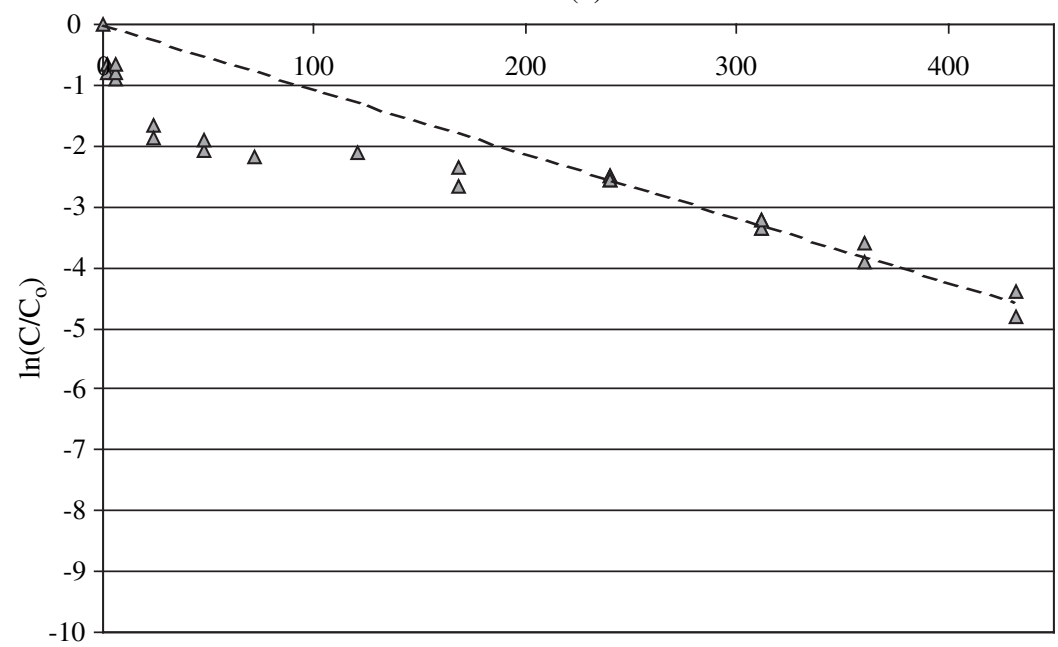

Figure 6: Degradation of PCE $(7.52 \mathrm{mg} / \mathrm{l})$ by the Brown zero-valent iron material. The dotted line represents the best fit using a first order kinetic model.

linear regression of the complete series of experimental data unreliable. However, a first order kinetic model may be applied to PCE, considering only the final part of the batch test $(t>240 \mathrm{~h}$ for the Brown material and $t>312 \mathrm{~h}$ for WSR material): a kinetic constant value equal to 0.0105 , in agreement with literature data, was obtained for the Brown material (see Fig. 6), and a kinetic constant value equal to 0.0101 was obtained for WSR material (see Fig. 7).

The faster dechlorination of PCE, compared to TCE, in the first phase of batch tests may be explained by hypothesizing its partial transformation into TCE by means of sequential hydrogenolysis (see Fig. 2). Moreover, after about 100-150 h, the dechlorination of PCE may become slower, 


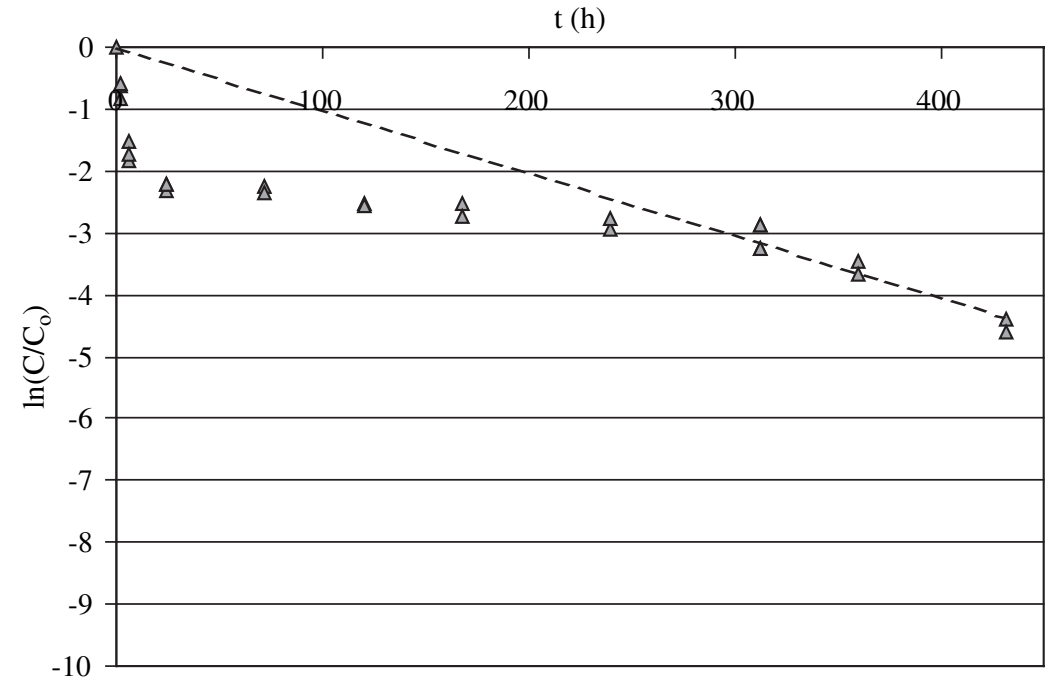

Figure 7: Degradation of PCE (7.52 mg/l) by WSR zero-valent iron material. The dotted line represents the best fit using a first order kinetic model.

Table 1: First order kinetic constants $(k)$, regression coefficients $\left(R^{2}\right)$ and half-life $\left(t_{1 / 2}\right)$ values for PCE and TCE reductive dechlorination by means of Brown and WSR zero-valent iron materials.

\begin{tabular}{lccc}
\hline & $k\left(\mathrm{~h}^{-1}\right)$ & $R^{2}$ & $t_{1 / 2}(\mathrm{~h})$ \\
\hline$T C E$ & & & \\
Brown & 0.0203 & 0.9807 & 33.14 \\
WSR & 0.0108 & 0.9853 & 64.18 \\
PCE & & & \\
Brown & 0.0105 & 0.9905 & 66.01 \\
WSR & 0.0101 & 0.9876 & 68.63 \\
\hline
\end{tabular}

compared to TCE: a competitive effect, affecting PCE, may be hypothesized. This is confirmed by literature data, showing kinetic constant values always higher for TCE than for PCE, and a competition between the two pollutants was proven in other studies [20].

A very important parameter obtainable from batch tests to evaluate the degradation efficiency of a reagent material is the half-life of the pollutants, according to the following equations:

$$
\begin{gathered}
C=\frac{C_{0}}{2}, \\
\ln \left(\frac{C_{0} / 2}{C_{0}}\right)=-k t_{1 / 2}, \\
t_{1 / 2}=\frac{\ln 2}{k} .
\end{gathered}
$$


Table 2: Necessary residence time $\left(T_{\text {perm }}\right)$ and required PRB thickness $(X)$ for TCE reductive dechlorination by means of Brown and WSR zero-valent iron materials.

\begin{tabular}{lcc}
\hline & $T_{\text {perm }}(\mathrm{h})$ & $X(\mathrm{~m})$ \\
\hline$T C E$ & & \\
Brown & 413 & 40 \\
WSR & 774 & 75 \\
\hline
\end{tabular}

$C_{0}=6.65 \mathrm{mg} / \mathrm{l}, C=1.5 \mu \mathrm{g} / \mathrm{l}$ (Italian law limit for TCE in groundwater), $v_{\mathrm{e}}=2.70 \times 10^{-5} \mathrm{~m} \mathrm{~s}^{-1}$.

The half-life $\left(t_{1 / 2}\right)$ values obtained from the experimental data are reported in Table 1, together with the first order kinetic constant $(k)$ and the regression coefficient $\left(R^{2}\right)$ values. The complete period of the batch tests was taken into account in the determination of the kinetic constant for TCE degradation ( $2 \mathrm{~h}<t<18$ days), and only the final phase ( 13 days $<t<18$ days) was considered for PCE.

On the grounds of the obtained kinetic constant and half-life values, the Brown material appears to be more efficient than the WSR material both in TCE and PCE degradations, although the difference between the two reagent media is more evident in TCE dechlorination because of the competitive effect that makes degradation of PCE slower.

To determine the implications for the considered field situation, the authors calculated, using the obtained $k$ values (see Table 1), the necessary residence time in a zero-valent iron PRB (by solving eqn (12), assuming that $C_{0}$ is the starting concentration of the pollutants and $C$ is the Italian law limit for TCE in groundwater, equal to $1.5 \mathrm{ppb}$ ). The calculation for PCE was not performed because the experimental data set for this pollutant can only partially be expressed by means of a first order kinetic. From the product of the gathered residence time values for the seepage velocity of the polluted flow $\left(v_{\mathrm{e}}=2.70 \times 10^{-5} \mathrm{~m} \mathrm{~s}^{-1}\right)$, the PRB thickness required to lower the TCE concentration to that below the Italian law limits for groundwater was calculated. The gathered results, reported in Table 2, are not applicable in the field (the maximum thickness for a PRB is usually equal to $0.6-1 \mathrm{~m}$, depending on its depth). Nevertheless, the authors demonstrated in another study [21] that considering a certain zero-valent iron material, column tests provide $k$ values that are three magnitude orders higher than batch tests (in the studied case, $k$ values equal to about $10^{-3} \mathrm{~s}^{-1}$ led to appropriate PRB thickness values). Therefore, to determine the implications for the considered polluted site, the performance of column tests should not be ignored.

The $\mathrm{pH}$, Eh, EC, concentration of chlorides, sulfates and several metals $(\mathrm{Na}, \mathrm{Mg}, \mathrm{Fe}, \mathrm{Mn}, \mathrm{Zn}$, $\mathrm{Cr}, \mathrm{Ni}, \mathrm{Pb}, \mathrm{Cu}, \mathrm{Cd}$ and $\mathrm{Co}$ ) were measured in the polluted aqueous phase resulting from batch tests and in the reagent blanks (artificial groundwater and zero-valent iron materials, without PCE and TCE).

The $\mathrm{pH}$ values obtained from samples and blanks are plotted against time in Fig. 8 (the initial value of artificial groundwater was equal to 7.11). Both samples behaved in the same way: $\mathrm{pH}$ values drastically decreased in the first $6 \mathrm{~h}$, then increased until 2 days, to decrease again and reach a minimum value after 3 days; the $\mathrm{pH}$ values then increased from 3 to 10 days, and stabilized around the initial value. On zero-valent iron materials, $\mathrm{HCl}$-washing is often performed by the iron producer to increase the surface area [22]; thus the initial decrease in $\mathrm{pH}$ may be due to the acid treatment, and the further increase may be due to the dechlorination process and the oxidation of zero-valent iron by water, dissolved oxygen and sulfates (see reactions (6), (7) and (8)). Both the initial decrease (probably 


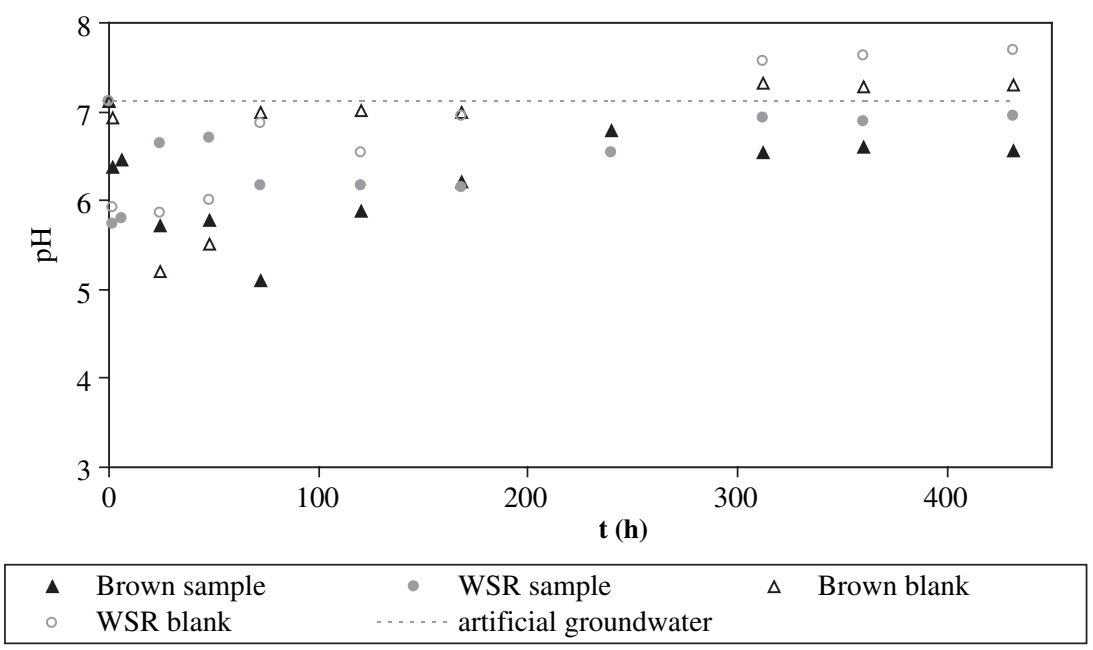

Figure 8: Aqueous phase $\mathrm{pH}$ vs. time in the Brown and WSR material with artificial groundwater in the presence (sample) and in the absence (blank) of PCE and TCE.

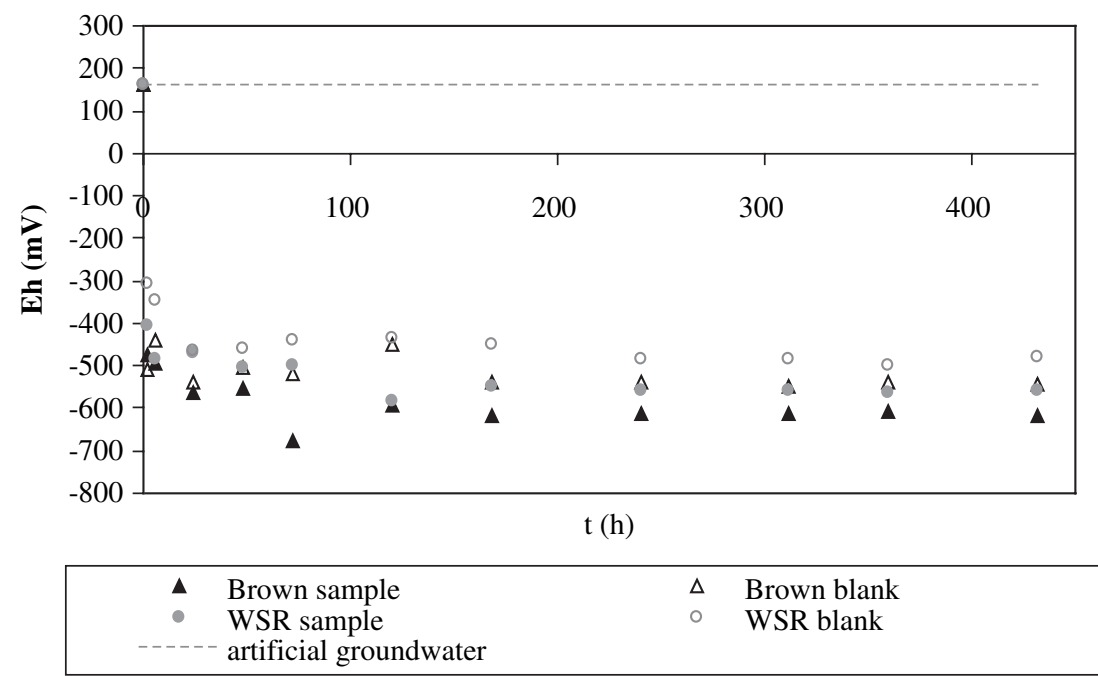

Figure 9: Aqueous phase redox potential (Eh) vs. time in the Brown and WSR material with artificial groundwater in the presence (sample) and in the absence (blank) of PCE and TCE.

due to a stronger $\mathrm{HCl}$-washing), and the later increase (due to iron oxidation) are stronger in the case of the Brown material. The $\mathrm{pH}$ values in the blanks showed similar trends: an initial decrease until 2 days, probably due to $\mathrm{HCl}$-washing, and stabilization to the artificial groundwater value after 3 days.

The Eh values are plotted against time in Fig. 9 (the initial value of artificial groundwater was equal to $+162 \mathrm{mV}$ ): for both samples, the zero-valent iron oxidation due to the dechlorination immediately caused a straight change of the Eh to negative values, typical of a reductive environment, in the first 


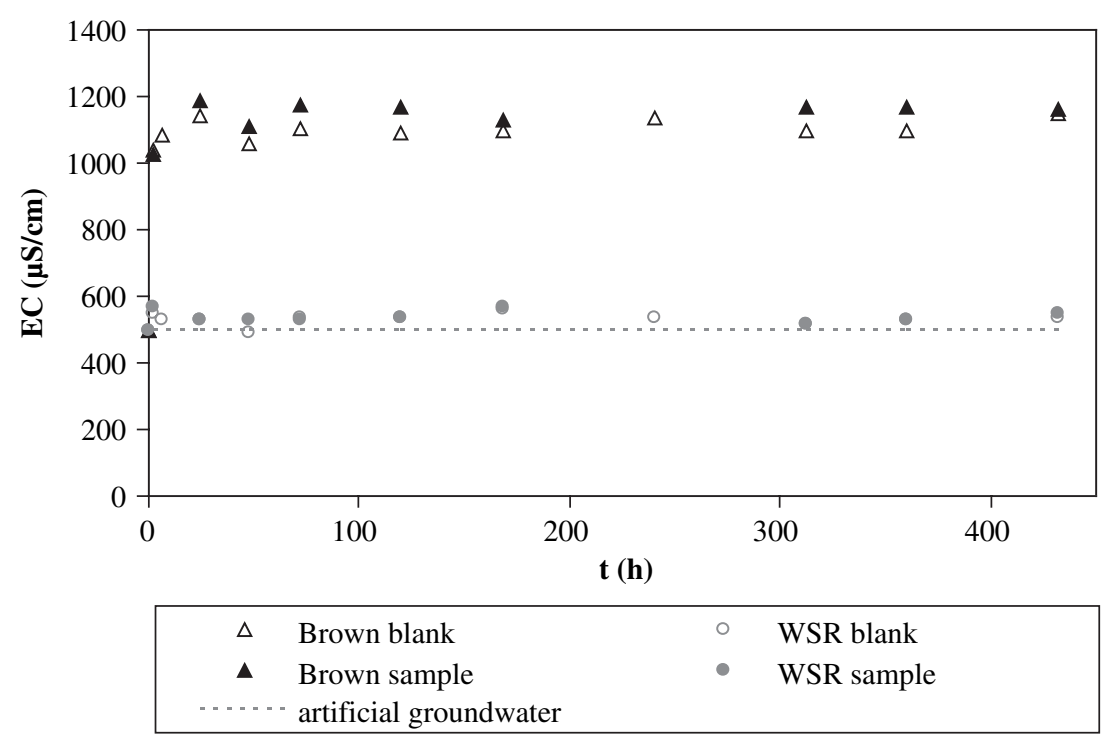

Figure 10: Aqueous phase electric conductivity (EC) vs. time in the Brown and WSR material with artificial groundwater in the presence (sample) and in the absence (blank) of PCE and TCE.

$2 \mathrm{~h}$ and reached the minimum values after $24 \mathrm{~h}$. The phenomenon was particularly strong in the case of the Brown material, which already proved to be more efficient than the WSR material. The Eh values then stabilized to about $560 \mathrm{mV}$ for the WSR sample and $-620 \mathrm{mV}$ for the Brown sample, creating more reductive conditions for the dechlorination process. The values of the blanks decreased in the first $6 \mathrm{~h}$, at a lower rate than the samples, and reached a minimum after $24 \mathrm{~h}$ where they stabilized around $-500 \mathrm{mV}$ : in the absence of chlorinated compounds, the zero-valent iron is oxidized just by water, dissolved oxygen and sulfates, thus creating less reductive conditions compared to the samples.

The EC values are plotted against time in Fig. 10 (the initial value of artificial groundwater was $500 \mu \mathrm{S} / \mathrm{cm}$ ): for the WSR material the EC values obtained from the samples and blanks are very similar and only slightly higher than the initial value; for the Brown material the values were double the initial value, and the values of the samples were higher than those of the blanks, probably because of an increase in the divalent iron and chloride ions due to dechlorination and various corrosion processes of the zero-valent material (see reactions (6), (7) and (8)). The fact that the values obtained from samples and blanks could be very similar allows the hypothesis that the EC in the case of WSR material increased mainly because of leaching processes from the substrates than of the dechlorination reaction.

The concentration values of chlorides, sulfates and some metals are reported in Table 3. The sodium concentration values are equal to those of the initial artificial groundwater for the WSR sample, but a strong increase instead is noticed for the Brown sample (see Table 3).

The magnesium concentration values strongly decrease for both samples after just $2 \mathrm{~h}$, until 5-7 days, when the values begin to increase slightly (see Table 3): this is probably due to the precipitation of magnesium as magnesium hydroxide. 
Table 3: Chemical composition of the aqueous phase during batch tests. All data are expressed in $\mathrm{mg} / \mathrm{l}$.

\begin{tabular}{lrcrcrcccc}
\hline & $\mathrm{Na}$ & $\mathrm{Mg}$ & $\mathrm{Fe}$ & $\mathrm{Mn}$ & $\mathrm{Zn}$ & $\mathrm{Co}$ & $\mathrm{Al}$ & $\mathrm{Cl}^{-}$ & $\mathrm{SO}_{4}^{2-}$ \\
\cline { 2 - 9 } $\begin{array}{l}\text { Artificial } \\
\text { groundwater }\end{array}$ & 100 & 20 & $<0.001$ & $<0.001$ & $<0.001$ & $<0.008$ & 0.44 & 128.04 & 50.22 \\
\hline Brown & & & & & & & & & \\
2 h & 228 & 10.4 & 84.1 & 0.50 & 0.037 & 0.008 & 0.46 & 330.26 & 42.29 \\
6h & 258 & 9.27 & 36.7 & 0.30 & $<0.001$ & 0.009 & 0.44 & 335.53 & 54.28 \\
1 days & 258 & 7.51 & 135.0 & 0.15 & 0.004 & 0.009 & 0.46 & 324.16 & 20.16 \\
2 days & 279 & 8.12 & 21.0 & 0.15 & $<0.001$ & 0.008 & 0.45 & 360.77 & 15.39 \\
3 days & 285 & 7.52 & 42.3 & 0.21 & 0.053 & 0.008 & 0.45 & 349.02 & 24.14 \\
5 days & 263 & 6.91 & 46.7 & 0.13 & $<0.001$ & 0.009 & 0.45 & 336.88 & 34.67 \\
7 days & 282 & 7.37 & 24.1 & 0.20 & $<0.001$ & 0.008 & 0.45 & 349.70 & 29.88 \\
10 days & 255 & 7.40 & 15.6 & 0.12 & $<0.001$ & 0.009 & 0.45 & 379.16 & 81.67 \\
13 days & 261 & 7.13 & 11.0 & 0.14 & 0.050 & 0.009 & 0.46 & 365.43 & 77.15 \\
WSR & & & & & & & & & \\
2 h & 99 & 14.0 & 121.0 & 0.72 & $<0.001$ & 0.009 & 0.45 & 170.13 & 92.50 \\
6h & 96 & 13.4 & 68.1 & 0.62 & $<0.001$ & 0.009 & 0.44 & 160.46 & 68.37 \\
1 days & 101 & 12.7 & 19.3 & 0.36 & $<0.001$ & 0.009 & 0.44 & 162.10 & 47.82 \\
2 days & 99 & 12.7 & 20.4 & 0.36 & $<0.001$ & 0.001 & 0.44 & 168.49 & 61.65 \\
3 days & 99 & 12.9 & 30.5 & 0.38 & 0.018 & 0.009 & 0.45 & 174.88 & 75.48 \\
5 days & 103 & 12.9 & 19.4 & 0.28 & $<0.001$ & 0.009 & 0.44 & 168.32 & 50.39 \\
7 days & 107 & 11.1 & 17.1 & 0.28 & 0.048 & 0.008 & 0.45 & 190.43 & 51.24 \\
10 days & 111 & 12.2 & 13.2 & 0.15 & $<0.001$ & 0.010 & 0.44 & 189.91 & 25.33 \\
13 days & 107 & 13.3 & 12.3 & 0.26 & 0.013 & 0.009 & 0.44 & 172.23 & 15.39 \\
\hline
\end{tabular}

The iron concentration values increase strongly for both samples in the first $6 \mathrm{~h}$ and then decrease constantly (see Table 3): this is mainly due to zero-valent iron oxidation to Fe(II) during the dechlorination process, but also happens because of zero-valent oxidation by water, dissolved oxygen and sulfates (as shown by relations (6), (7) and (8)). The decrease in the values of iron concentration is probably due to $\mathrm{Fe}(\mathrm{II})$ precipitation as hydroxide.

The manganese concentration values initially increase $(t<6 \mathrm{~h}$ ), then decrease constantly (see Table 3): this metal is probably contained in the two cast iron aggregates as an impurity, especially in the WSR material, and may also precipitate as hydroxide.

The zinc concentration values increase in several cases (see Table 3): probably because the metal is present at trace levels in the studied materials, and the absence of any trend may be due to heterogeneity of solid samples.

No releases of chromium, nickel, lead, copper, cadmium, cobalt and aluminum were measured in the polluted aqueous phase from the reagent materials.

The chloride concentration values increase strongly in the first 2-6h (see Table 3), as much as double the initial value for the Brown sample, and then the rate of increase slows: this is essentially due to the HCl-washing performed by the producer to enhance the removal efficiency. In Fig. 11, the chloride concentration values are compared for blanks and samples obtained from the Brown and the 


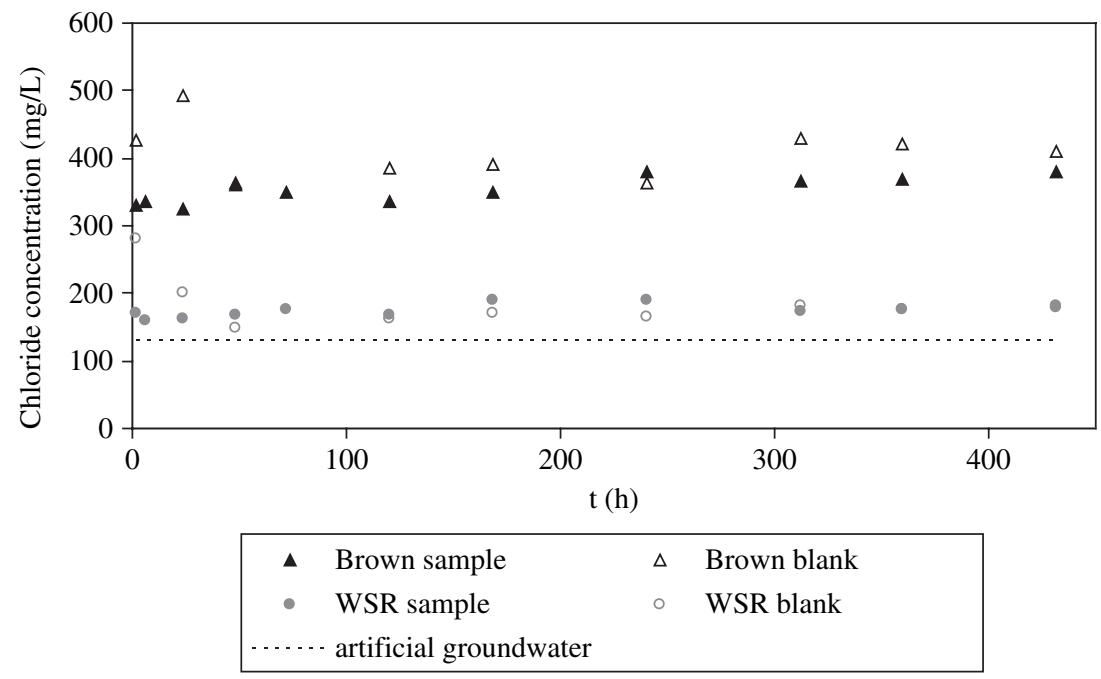

Figure 11: Chloride concentration values vs. time in the Brown and WSR material with artificial groundwater in the presence (sample) and in the absence (blank) of PCE and TCE.

WSR materials: there is no substantial difference between the chloride content of the samples and the blanks. The batch tests, in this case, do not allow the evaluation of the release of chloride due to dechlorination reactions.

The sulfate concentration values show different trends for the two materials (see Table 3): in the case of the Brown sample, the sulfate content remains around the initial value for the first $6 \mathrm{~h}$, then it decreases, to increase again after 3 days. In the case of the WSR sample, the concentration becomes double that of the initial value after $2 \mathrm{~h}$; then it shows a decreasing trend after $24 \mathrm{~h}$, increases again for 1-5 days and then finally decreases to reach the minimum values. The decreasing phases are probably caused by the oxidation of zero-valent iron materials to $\mathrm{Fe}(\mathrm{II})$ by sulfates (see reaction (7)), involving the formation of sulfidric acid. Besides, the WSR material has a higher sulfur content than the Brown material.

The sulfate concentration values for blanks and samples obtained from the Brown and the WSR materials during batch tests are compared in Fig. 12: the concentration values are higher for the blanks than the samples, thus confirming the existence of reaction (7), which mostly happens in the presence of PCE and TCE, due to the prevalent corrosion phenomena.

\section{CONCLUSIONS}

Based on the results of the batch tests performed, the following hypotheses may be formulated:

- TCE dechlorination by both reagent materials can be expressed correctly using a first order kinetic model, obtaining values in agreement with the data in literature.

- A first order kinetic model may be reliably applied to PCE and both reagent materials considering only the final part of the test $(t>10-13$ days), obtaining $\mathrm{k}$ values in agreement with the data in literature regarding batch tests.

- Faster dechlorination of PCE, compared to TCE, in the first phase of batch tests apparently lowers the rate of TCE degradation. After about $150 \mathrm{~h}$, the dechlorination of PCE may become slower, compared to TCE: a competitive effect, affecting PCE, may be hypothesized. 


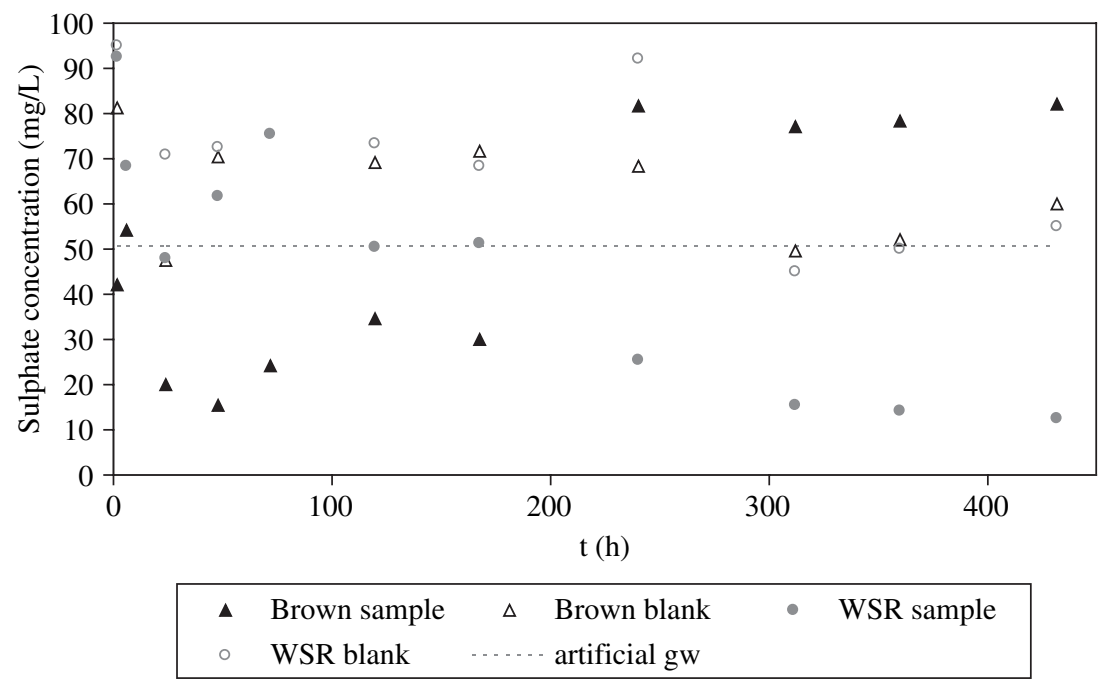

Figure 12: Concentration values of sulfates vs. time in the Brown and WSR material with artificial groundwater in the presence (sample) and in absence (blank) of PCE and TCE.

- The Brown material appears to be more efficient than the WSR material, both in TCE and PCE degradation, although the difference between the two reagent media is more evident in TCE dechlorination because of the competitive effect that makes PCE degradation slower. The higher efficiency of the Brown substrate is probably due to its different composition, as confirmed by the leaching of chemical species in aqueous phase (see later), compared to the WSR material.

- The $\mathrm{pH}$ and Eh values measured in the aqueous phase obtained from batch tests confirm a higher degradation efficiency of the Brown material, and therefore $\mathrm{HCl}$-washing of the reagent substrates may be hypothesized.

- The EC and chloride and sodium concentration values indicate the release of these chemical species in the aqueous phase, especially with the Brown material. Moreover, the WSR material has a higher sulfur content than the Brown material.

- The formation of a surface passivation layer made of iron, manganese and magnesium hydroxides, iron and magnesium carbonates and other corrosion products may be hypothesized.

- No toxic metals $(\mathrm{Cr}, \mathrm{Ni}, \mathrm{Pb}, \mathrm{Cu}, \mathrm{Cd}, \mathrm{Co}$ and $\mathrm{Al})$ were released in the aqueous phase by zero-valent materials.

This study confirms the efficiency of zero-valent iron materials in the remediation of chlorinated solvents: this work may be considered a starting point for the evaluation of the feasibility of a PRB in the considered site. The correct PRB dimensioning will be performed by means of column tests and a complete characterization of the investigated site and of the pollutant plume.

\section{REFERENCES}

[1] Morales, J., Hutcheson, R. \& Cheng, I.F., Dechlorination of chlorinated phenols by catalyzed and uncatalyzed $\mathrm{Fe}(0)$ and $\mathrm{Mg}(0)$ particles. Journal of Hazardous Materials, B90, pp. 97-108, 2002.

[2] Navon, D., Loehr, R.C., Liljestrand, H.M. \& Daniel, D.E., Impact of biodegradable trenching slurry on iron treatment wall performance. Water Science Technology, 38(7), pp. 49-53, 1998. 
[3] Powell, R.M. \& Puls, R.W., Proton generation by dissolution of intrinsic or augmented aluminosilicate minerals for in situ contaminant remediation by zero-valence-state iron. Environmental Science and Technology, 31(8), pp. 2244-2251, 1997.

[4] Zanetti, M.C., Fiore, S. \& Genon, G., Contaminated aquifer remediation by means of zero-valent barriers. Proceedings of the IV International Conference Biological Processing of Organics ORBIT 2003, Perth, Australia, pp. 572-579, 30 April-2 May 2003.

[5] Helland, B.R., Alvarez, P.J.J. \& Schnoor, J.L., Reductive dechlorination of carbon tetrachloride with elemental iron. Journal of Hazardous Materials, 41, pp. 205-216, 1995.

[6] Matheson, L.J. \& Tratnyek, P.G., Reductive dehalogenation of chlorinated methanes by iron metal. Environmental Science and Technology, 28(12), pp. 2045-2053, 1994.

[7] Lee, T., Tokunaga, T., Suyama, A. \& Furukawa, K., Efficient dechlorination of tetrachloroethylene in soil slurry by combined use of an anaerobic desulfitobacterium sp. strain Y-51 and zero-valent iron. Journal of Bioscience and Bioengineering, 92(5), pp. 453-458, 2001.

[8] Butler, E.C. \& Hayes, K.F., Factors influencing rates and products in the transformation of trichloroethylene by iron sulfide and iron metal. Environmental Science and Technology, 35(19), pp. 3884-3891, 2001.

[9] Gillham, R.W. \& O'Hannesin, S.F., Enhanced degradation of halogenated aliphatics by zerovalent iron. Ground Water, 32(6), pp. 958-967, 1994.

[10] Scherer, M.M., Balko, B.A., Gallagher, D.A. \& Tratnyek, P.G., Correlation analysis of rate constants for dechlorination by zero-valent iron. Environmental Science and Technology, 32(19), pp. 3026-3033, 1998.

[11] Agrawal, A., Ferguson, W.J., Gardner, B.O., Christ, J.A., Bandstra, J.Z. \& Tratnyek, P.G., Effects of carbonate species on the kinetics of dechlorination of 1,1,1-trichloroethane by zero-valent iron. Environmental Science and Technology, 36(20), pp. 4326-4333, 2002.

[12] Gotpagar, J., Grulke, E., Tsang, T. \& Bhattacharyya, D., Reductive dehalogenation of trichloroethylene using zero-valent iron. Environmental Progress, 16(2), pp. 137-143, 1997.

[13] Furukawa, Y., Kim, J., Watkins, J. \& Wilkin, R.T., Formation of ferrihydrite and associated iron corrosion products in permeable reactive barriers of zero-valent iron. Environmental Science and Technology, 36(24), pp. 5469-5475, 2002.

[14] Vogan, J.L., Focht, R.M., Clark, D.K. \& Graham, S.L., Performance evaluation of a permeable reactive barrier for remediation of dissolved chlorinated solvents in groundwater. Journal of Hazardous Materials, 68, pp. 97-108, 1999.

[15] Zhang, W., Wang, C. \& Lien, H., Treatment of chlorinated organic contaminants with nanoscale bimetallic particles. Catalysis Today, 40, pp. 387-395, 1998.

[16] Roberts, A.L., Totten, L.A., Arnold, W.A., Burris, D.R. \& Campbell, T.J., Reductive elimination of chlorinated ethylenes by zero-valent metals. Environmental Science and Technology, 30(8), pp. 2654-2659, 1996.

[17] Orth, R., Asce, F., Dauda, T. \& McKenzie, D.E., Reductive dechlorination of DNAPL trichloroethylene by zero-valent iron. Practice Periodical of Hazardous, Toxic and Radioactive Waste Management, pp. 123-128, July 1998.

[18] APHA, AWWA, WPCF, Standard methods for the examination of water and wastewater, 20th edn., APHA: New York, 1998.

[19] Gotpagar, J.K., Grulke, E.A. \& Bhattacharyya, D., Reductive dehalogenation of trichloroethylene: kinetic models and experimental verification. Journal of Hazardous Materials, 62, pp. 243-264, 1998. 
[20] Burris, D.R., Campbell, T.J. \& Manoranjan, V.S., Sorption of trichloroethylene and tetracholoroethylene in a batch reactive metallic iron-water system. Environmental Science and Technology, 29(11), pp. 2850-2855, 1995.

[21] Zanetti, M.C. \& Fiore, S., Evaluation of mutual connections between zero-valent iron reactivity and groundwater composition in trichloroethylene degradation, Annali di Chimica, Journal of Analytical, Environmental and Cultural Heritage Chemistry, 95(11-12), pp. 779-789, 2005.

[22] Su, C. \& Puls, R.W., Kinetics of trichloroethylene reduction by zerovalent iron and tin: pretreatment effect, apparent activation energy and intermediate products. Environmental Science and Technology, 33(1), pp. 163-168, 1999. 